\title{
2013 Yılı Yaşam Memnuniyeti Araştırması Sonuçlarının İl Bazlı Ekonomik, Sosyal ve Siyasi Analizi
}

\author{
Furkan Beşel*
}

Sakarya Üniversitesi, Siyasal Bilgiler Fakültesi, Maliye Bölümü, Sakarya

\begin{abstract}
Öz
Bu çalışmada, Türkiye İstatistik Kurumu tarafindan 2013 yılında il düzeyinde yapılan, "Yaşam Memnuniyeti Araştırması" sonuçlarına göre en mutlu ve en mutsuz illere ait göstergeler ekonomik, sosyal ve siyasi (2009-2014 yerel seçimleri) açıdan analiz edilmiştir. Elde edilen sonuçlara göre mutlu illerde mutsuz illere kıyasla; işsizlik oranları, konut satıs sayısı oranları, genel bütçe vergi gelirlerinde toplam tahsilat içindeki payı, genel bütçe vergi gelirleri tahsilat/tahakkuk oranı, boşanma hızı, kişi başına elektrik tüketimi, nüfus yoğunluğu daha düşük iken; bin kişi başına otomobil sayısı, ev sahibi olan hanehalkı oranı, ilkokullarda net okullaşma oranı ve yüz bin kişi başına hastane yatak sayısı daha fazladır. Ayrıca 2014 yerel seçimleri sonuçlarına göre mutlu illerin belediye yönetiminde siyasi parti tercihi değişmemişken mutsuz illerin ikisinde belediye yönetimi el değiştirmişstir.
\end{abstract}

Anahtar Kelimeler: Yaşam memnuniyeti araştırması, Mutluluk ekonomisi

\section{Economic, Social and Political Analysis of Life Satisfaction Research Results by Provinces}

\begin{abstract}
This study examines "Life Satisfaction Research" results for happiest and most unhappy provinces by the perspective economic, social and political (2009-2014 local elections) which was made by Turkish Statistical Institute by provinces in 2013. According to the results obtained; in happy provinces unemployment rates, number of residential sales rates, share of total tax revenues in the total collection, general budget tax revenue collection / accrual rate, divorce rate, per capita electricity consumption, population density are less than unhappy provinces. However, number of cars per thousand people, rate of households with home owners, net enrollment ratio in primary schools and number of hospital beds per hundred thousand people are more than unhappy provinces. Furthermore, according to the results of the 2014 local elections, the municipal administration of the happy provinces unchanged but in two of unhappy provinces the municipal administration has changed.
\end{abstract}

Key words: Life satisfaction research, Happiness economics

\section{GİRIŞ}

Bireyin yaşam kalitesini genel olarak değerlendirmesi ile ulaşılan olumluluk düzeyi (Veenhoven, 1996: 17) şeklinde tanımlanan yaşam memnuniyetini belirleyen ekonomik, sosyal ve siyasi birçok bileşen bulunmaktadır. Yaşam memnuniyetine benzer olan "yaşam doyumu" kavramı Neugarten tarafından ilk defa 1961'de kullanılmıştır. Bir insanın beklentileri ve elinde olanların karşılanması ile elde edilen durum ya da sonuç şeklinde tanımlanan yaşam doyumunun belirleyicileri olarak 
cinsiyet, yaş, eğitim, gelir, sosyal köken, medeni durum, sağlık, sosyal ilişkiler ağı, sosyal etkinlik düzeyi gösterilmektedir (Karataş, 1990: 106).

Yaşam kalitesi; kişinin yaşamdaki statüsünü, yaşadığı yer ve hedefleri, beklentileri, yaşam standartları ve kaygıları ile ilişkili olarak kültürel ve değer sistemleri kapsamında algılamasıdır. Yaşam memnuniyetini tek başına belirlemedikleri gerçeğiyle birlikte en azından etkileyen faktörler arasında, bireylerin istihdam olanakları, konut sahibi olmaları, bireyler üzerindeki vergi baskısı ve yükü gibi ekonomik faktörler; boşanma hızı, nüfus yoğunluğu gibi sosyal faktörler ve yaşadıkları mahalli idareleri yöneten siyasi iktidar gibi siyasal faktörler gösterilebilir. Yaşam memnuniyetinin belirleyicileri olarak gelir düzeyinin yanı sıra mekânsal, toplumsal hatta siyasal faktörlerin de etkisi olduğu söylenebilir (Pacione, 2003: 19).

Yaşam Memnuniyeti Araştırmasının (YMA) amacı TÜIK tarafından "Bireyin genel mutluluk algısını, toplumsal değerlerini, temel yaşam alanlarındaki genel memnuniyetini ve bu alanlardaki kamu hizmetlerinden memnuniyetini ölçmek ve bu memnuniyet düzeyinin zaman içindeki değişimini takip etmek" şeklinde ifade edilmektedir.

Araştırma, Türkiye Cumhuriyeti sınırları içinde bulunan hanelerde yaşayan 18 ve daha yukarı yaştaki Türkiye Cumhuriyeti vatandaşları ile yabancı uyruklu kişileri kapsamakta olup araştırmada, kurumsal nüfus (üniversite öğrenci yurdu, huzurevi, bakımevi, ceza ve tutukevi, sslahevi, yetiştirme yurdu, askeri birlik ve kışla vb.) kapsam dişında tutulmaktadır.

İlk kez 2003'te Hanehalkı Bütçe Anketi'ne bir modül olarak eklenen ve uygulanan araştırma 2004 sonrası yıllarda bağımsız olarak uygulanmaktadır. Araştırma ilk defa 2013 yılında, il düzeyinde tahmin verebilecek şekilde tasarlanmıştır. 2013 yılında araştırmanın örneklem büyüklüğü, İstatistiki Bölge Birimleri Sınıflaması (İBBS) Düzey 3 (81 il) bazında tahmin üretecek şekilde hesaplanmıştır. Demografik bilgiler tüm hanehalkı bireylerinden alınmakta iken yaşam memnuniyetine ilişkin sorular hanehalkında bulunan 18 ve daha yukarı yaştaki bireylere sorulmaktadır.

\section{Yaşam Memnuniyeti Araştırması Sonuçları (2013)}

Araştırma kapsamında, 2013 y1lında Türkiye genelinde 125.720 haneye gidilerek, 18 ve daha yukarı yaştaki 196.203 birey ile yüz yüze görüşmeler yapılmıştır. Elde edilen sonuçlara göre en mutlu ve en mutsuz beş il aşağıdaki tabloda sunulmuştur. 
Tablo 1. İllere Göre Mutluluk Düzeyi, 2013

\begin{tabular}{lclc}
\hline En Yüksek İller & $\%$ & En Düşük İller & $\%$ \\
\hline Sinop & 77.7 & Tunceli & 42.0 \\
Afyonkarahisar & 76.4 & Osmaniye & 45.8 \\
Bayburt & 75.9 & Diyarbakır & 48.7 \\
Kirıkkale & 75.5 & Antalya & 49.8 \\
Kütahya & 73.8 & Hatay & 50.3 \\
\hline & TÜRKIYYE GENELİ ORTALAMA: \%59 \\
\hline
\end{tabular}

Kaynak: TÜiK

Mutlu olduğunu beyan eden bireylerin oranı 2013 yılında ülke genelinde \%59 olarak tahmin edilmiştir. Mutlu olduğunu beyan eden bireylerin oranının en yüksek olduğu il, \%77,7 ile Sinop iken mutlu olduğunu beyan eden bireylerin oranının en düşük olduğu ilin ise \%42 ile Tunceli olduğu gözlemlenmiştir.

Yaşam memnuniyetin en fazla olduğu 5 il arasına sosyo-ekonomik gelişmişlik seviyesi yüksek olan illerin girmemesi dikkat çekmektedir.

\subsection{Ekonomik Göstergeler Bağlamında Değerlendirme}

Yayımlanan il bazlı ekonomik göstergelerin çok sınırlı olması çalışmanın en önemli sınırlılığını oluşturmaktadır. Bu bölümde ulaşılabilen veriler kapsamında en mutlu ve en mutsuz beş il için değerlendirmeler yapılacaktır.

\section{İşsizlik Oranları}

Yaşam memnuniyetinde işsizlik oranlarının etkisini analiz etmek amacıyla il bazlı işsizlik oranları en mutlu ve en mutsuz beş il için değerlendirilmiştir.

Tablo 2. İssizizlik Oranları Karşılaştırması (2013)

\begin{tabular}{llll}
\hline En Mutlu İller & $\%$ & En Mutsuz İller & $\%$ \\
\hline Sinop & $6.2(-)$ & Tunceli & $8.1(-)$ \\
Afyonkarahisar & $5.6(-)$ & Osmaniye & $14.0(+)$ \\
Bayburt & $6.2(-)$ & Diyarbakır & $18.7(+)$ \\
Kirıkkale & $8.0(-)$ & Antalya & $7.9(-)$ \\
Kütahya & $6.0(-)$ & Hatay & $12.2(+)$ \\
\hline
\end{tabular}

TÜRKIYE GENELİ ORTALAMA: \%9.0

\section{Kaynak: TÜİK}

Not: Parantez içindeki “+" ve “-” işaretleri sırasıyla değişkenin Türkiye ortalamasının üstünde veya altında olduğunu ifade etmektedir.

İl bazlı işsizlik oranları (2013) incelendiğinde YMA'da en mutlu olan beş ilin tamamında işsizlik oranlarının Türkiye ortalamasının altında olduğu; mutsuz illerde ise işsizliğin ortalamanın üstünde veya ortalamaya çok yakın olduğu gözlemlenmektedir. Bu bağlamda işsizlik oranlarının, bireylerin yaşam memnuniyetine etki eden önemli bir faktör olduğu söylenebilir. 


\section{Konut Satış Sayısı}

İllerde yapılan konut satış sayılarının Türkiye geneline oranı karşılaştırılarak YMA'da mutluluk üzerinde etkisi olup olmadığı araştırılmıştır.

Tablo 3. Konut Satış Sayısı Karşılaştırması (2013)

\begin{tabular}{lclc}
\hline En Mutlu İller & $\%$ & En Mutsuz İler & $\%$ \\
\hline Sinop & 0.12 & Tunceli & 0.10 \\
Afyonkarahisar & 0.38 & Osmaniye & 0.42 \\
Bayburt & 0.03 & Diyarbakır & 1.55 \\
Kirıkkale & 0.37 & Antalya & 4.93 \\
Kütahya & 0.62 & Hatay & 0.73 \\
\hline
\end{tabular}

Kaynak: TÜiK

Elde edilen sonuçlar bağlamında mutlu illerin konut satış sayısı oranının mutsuz illere kıyasla daha düşük olduğu görülmektedir. Bu durumu YMA sonuçları ile değerlendirdiğimizde konut satışının bireyleri pek mutlu etmediğini söylemek yanlış olmasa gerek.

\section{Bin Kişi Başına Otomobil Sayısı}

İl bazlı ekonomik göstergelerden bin kişi başına düşen otomobil sayısı için elde edilen sonuçlar Tablo 4'te gösterilmiştir.

Tablo 4. Bin Kişi Başına Otomobil Sayısı Karşılaştırması (2012)

\begin{tabular}{lclc}
\hline En Mutlu İller & $\begin{array}{c}\text { Otomobil Sayısı } \\
\text { (Bin Kişi Başına) }\end{array}$ & En Mutsuz İler & $\begin{array}{c}\text { Otomobil Sayısı } \\
\text { (Bin Kişi Başına) }\end{array}$ \\
\hline Sinop & $113(-)$ & Tunceli & $26(-)$ \\
Afyonkarahisar & $89(-)$ & Osmaniye & $106(-)$ \\
Bayburt & $56(-)$ & Diyarbakır & $30 \quad(-)$ \\
Kirıkkale & $117(+)$ & Antalya & $163(+)$ \\
Kütahya & $139(+)$ & Hatay & $94 \quad(-)$ \\
\hline
\end{tabular}

Kaynak: TÜIK

Not: Parantez içindeki “+" ve "_" işaretleri sırasıyla değişkenin Türkiye ortalamasının üstünde veya altında olduğunu ifade etmektedir.

Mutsuz illerden sadece Antalya'da bin kişi başına düşen otomobil sayısı Türkiye ortalamasının üstündeyken; mutlu illerde Kütahya ve Kırıkkale ortalamanın üstünde, Sinop neredeyse ortalama ile aynı düzeydedir. Bu bağlamda bireylerin otomobil sahibi olmalarının mutluluğu arttırdığı söylenebilir.

\section{Ev Sahibi Olan Hanehalkı}

İ bazlı ev sahibi olan hane halkı veri seti en son 2011'de yayınlanmıştır. 
Tablo 5. Ev Sahibi Olan Hanehalkı Karşılaştırması (2011)

\begin{tabular}{lclc}
\hline En Mutlu İller & $\%$ & En Mutsuz İller & $\%$ \\
\hline Sinop & $73.68(+)$ & Tunceli & $62.73(-)$ \\
Afyonkarahisar & $75.63(+)$ & Osmaniye & $74.36(+)$ \\
Bayburt & $71.32(+)$ & Diyarbakır & $75.08(+)$ \\
Kirıkkale & $70.14(+)$ & Antalya & $63.17(-)$ \\
Kütahya & $68.90(+)$ & Hatay & $72.01(+)$ \\
\hline
\end{tabular}

Kaynak: TÜİK

Not: Parantez içindeki “+" ve "_" işaretleri sırasıyla değişkenin Türkiye ortalamasının üstünde veya altında olduğunu ifade etmektedir.

YMA sonuçlarına göre en mutlu olduğu belirlenen beş ilde ev sahibi olan hanehalkı oranları en mutsuz olan illerdeki oranlara kıyasla -genel olarak- daha yüksektir. Ayrıca mutlu illerin tamamında ev sahibi olma oranı Türkiye ortalamasının üstündedir. Bireylerin ev sahibi olmalarının mutlulukları üzerinde etkili olduğu söylenebilir.

\section{Genel Bütçe Vergi Gelirlerinde Toplam Tahsilat İçindeki Payı}

Gelir İdaresi Başkanlığı verilerine göre 2013 yılı için genel bütçe vergi gelirlerinde toplam tahsilat içindeki payı Tablo 6' da sunulmuştur.

Tablo 6. Genel Bütçe Vergi Gelirlerinde Toplam Tahsilat İçindeki Payı Karşılaştırması (2013)

\begin{tabular}{lclc}
\hline En Mutlu İller & $\%$ & En Mutsuz İller & $\%$ \\
\hline Sinop & 0.05 & Tunceli & 0.02 \\
Afyonkarahisar & 0.19 & Osmaniye & 0.09 \\
Bayburt & 0.01 & Diyarbakir & 0.32 \\
Kirıkkale & 0.25 & Antalya & 1.39 \\
Kütahya & 0.18 & Hatay & 1.07 \\
\hline
\end{tabular}

Kaynak: Gelir İdaresi Başkanlığ1

Mutsuz illerin genel bütçe vergi gelirleri tahsilatı toplamı içindeki payının mutlu illere kıyasla daha yüksek olduğu söylenebilir. Daha çok vergi ödüyor olmanın bireylerin mutsuzluğunda etkili olduğu söylenebilir.

\section{Genel Bütçe Vergi Gelirleri Tahsilat/Tahakkuk Oranı}

Tahakkuk eden vergilerin tahsil edilme oranları 2013 yılı için Türkiye genelinde \%85.4'tür. YMA bağlamında en mutlu illerden sadece Kırıkkale'de bu oran Türkiye ortalamasının üstünde iken; en mutsuz illerde ise Tunceli ve Hatay'da ortalamanın üstündedir. 
Tablo 7. Genel Bütçe Vergi Gelirleri Tahsilat/Tahakkuk Oranı Karşılaştırması (2013)

\begin{tabular}{lclc}
\hline En Mutlu İller & $\%$ & En Mutsuz İller & $\%$ \\
\hline Sinop & $71.5(-)$ & Tunceli & $90.0(+)$ \\
Afyonkarahisar & $71.1(-)$ & Osmaniye & $63.4(-)$ \\
Bayburt & $82.7(-)$ & Diyarbakır & $70.7(-)$ \\
Kırıkkale & $88.2(+)$ & Antalya & $72.8(-)$ \\
Kütahya & $70.2(-)$ & Hatay & $85.9(+)$ \\
\hline
\end{tabular}

TÜRKIYE GENELİ ORTALAMA: \%85.4

Kaynak: Maliye Bakanlığı, Muhasebat Genel Müdürlüğü

Not: Parantez içindeki "+" ve “-" işaretleri sırasıyla değişkenin Türkiye ortalamasının üstünde veya altında olduğunu ifade etmektedir.

Genel olarak mutsuz illerde bu oranın mutlu illere göre ortalama olarak daha yüksek olduğu söylenebilir. Tahakkuk eden vergilerini ödeyen bireylerin (Tahsilat/Tahakkuk oranı arttıkça) daha mutsuz olduğu sonucuna ulaşılabilir.

\subsection{Sosyal Göstergeler Bağlamında Değerlendirme}

Çalışmanın bu bölümünde YMA sonuçlarına göre en mutlu ve en mutsuz beş il için ulaşılabilen sosyal göstergeler karşılaştırılarak analiz edilecektir.

\section{Boşanma Hızı}

2012 yılı için Türkiye genelinde boşanma hızı binde 1.64'tür. Tablo 8'de görüldügü üzere genel olarak mutlu illerde boşanma hızının mutsuz illere kıyasla daha az olduğu söylenebilir.

Tablo 8. Boşanma Hızı Karşılaştırması (2012)

\begin{tabular}{lclc}
\hline En Mutlu İller & $\begin{array}{c}\text { Boşanma Hızı } \\
\text { (binde) }\end{array}$ & En Mutsuz Iller & $\begin{array}{c}\text { Boşanma Hızı } \\
\text { (binde) }\end{array}$ \\
\hline Sinop & $1.30(-)$ & Tunceli & $1.49(-)$ \\
Afyonkarahisar & $1.32(-)$ & Osmaniye & $1.44(-)$ \\
Bayburt & $0.59(-)$ & Diyarbakır & $0.49(-)$ \\
Kırıkale & $1.87(+)$ & Antalya & $2.59(+)$ \\
Kütahya & $1.63(-)$ & Hatay & $1.38(-)$ \\
\hline
\end{tabular}

\section{Kaynak: TÜİK}

Not: Parantez içindeki “+" ve "_" işaretleri sırasıyla değişkenin Türkiye ortalamasının üstünde veya altında olduğunu ifade etmektedir.

Boşanma hızı (2012) verileri iller bazında değerlendirildiğinde mutlu illerden sadece Kırıkkale; mutsuz illerden ise sadece Antalya Türkiye ortalamasının üstünde seyretmiştir.

\section{İlkokullarda Net Okullaşma Oranı}

2012 yılı için Türkiye genelinde ilkokullarda net okullaşma oranı \%98.86'dır. 
Tablo 9. İlkokullarda Net Okullaşma Oranı Karşılaştırması (2012)

\begin{tabular}{lclc}
\hline En Mutlu İller & $\%$ & En Mutsuz İller & $\%$ \\
\hline Sinop & $99.4(+)$ & Tunceli & $97.69(-)$ \\
Afyonkarahisar & $98.36(-)$ & Osmaniye & $98.30(-)$ \\
Bayburt & $99.26(+)$ & Diyarbakır & $99.64(+)$ \\
Kirıkkale & $96.82(-)$ & Antalya & $97.93(-)$ \\
Kütahya & $99.08(+)$ & Hatay & $98.62(-)$ \\
\hline
\end{tabular}

Kaynak: TÜiK

Not: Parantez içindeki “+" ve "_" işaretleri sırasıyla değişkenin Türkiye ortalamasının üstünde veya altında olduğunu ifade etmektedir.

Mutlu illerde ilkokullarda net okullaşma oranı mutsuz illere göre genel olarak daha yüksektir. Eğitime yapılan harcamaların mutluluğu arttırdığı söylenebilir.

\section{Yüz Bin Kişi Başına Hastane Yatak Sayısı} 252 'dir.

2011 yılı için Türkiye genelinde yüz bin kişi başına düşen hastane yatak sayısı

Tablo 10. Yüz Bin Kişi Başına Hastane Yatak Sayısı Karşılaştırması (2011)

\begin{tabular}{lclc}
\hline En Mutlu İller & $\begin{array}{c}\text { Yatak Sayısı } \\
\text { (Yüz Bin Kişi } \\
\text { Başına) }\end{array}$ & En Mutsuz İller & $\begin{array}{c}\text { Yatak Sayısı } \\
\text { (Yüz Bin Kişi } \\
\text { Başına) }\end{array}$ \\
\hline Sinop & $246(-)$ & Tunceli & $214(-)$ \\
Afyonkarahisar & $274(+)$ & Osmaniye & $181(-)$ \\
Bayburt & $196(-)$ & Diyarbakır & $254(+)$ \\
Kırıkale & $350(+)$ & Antalya & $237(-)$ \\
Kütahya & $301(+)$ & Hatay & $168(-)$ \\
\hline
\end{tabular}

Kaynak: TÜIKK

Not: Parantez içindeki “+" ve "-" işaretleri sırasıyla değişkenin Türkiye ortalamasının üstünde veya altında olduğunu ifade etmektedir.

Mutlu illerde kişi başına hastane yatak sayısı genel olarak Türkiye ortalamasının üzerinde iken mutsuz illerde sadece Diyarbakır'da -ki ortalamaya çok yakın- ortalamanın üzerindedir. Mutlu illerde kişi başına hastane yatak sayısı mutsuz illere kıyasla daha fazladır. Sağlık harcamalarının mutluluk üzerinde olumlu etkisi olduğu söylenebilir.

\section{Kişi Başına Elektrik Tüketimi}

2011 yılı için Türkiye genelinde kişi başına elektrik tüketimi 2.490 KWh'dır. 
Tablo 11. Kişi Başına Elektrik Tüketimi Karşılaştırması (2011)

\begin{tabular}{llll}
\hline En Mutlu İller & KWh & En Mutsuz İller & KWh \\
\hline Sinop & $1.573(-)$ & Tunceli & $1.050(-)$ \\
Afyonkarahisar & $1.693(-)$ & Osmaniye & $5.108(+)$ \\
Bayburt & $987(-)$ & Diyarbakır & $845(-)$ \\
Kirıkkale & $2.091(-)$ & Antalya & $3.005(+)$ \\
Kütahya & $2.345(-)$ & Hatay & $3.503(+)$ \\
\hline
\end{tabular}

Kaynak: TÜIKK

Not: Parantez içindeki “+" ve "_" işaretleri sırasıyla değişkenin Türkiye ortalamasının üstünde veya altında olduğunu ifade etmektedir.

Mutlu illerin tamamında kişi başına elektrik tüketimi Türkiye ortalamasının altında iken mutsuz illerde genellikle ortalamanın üzerindedir. Elektrik tüketimini teknolojik araç gereç kullanımı ile bağdaştırırsak teknolojinin aslında mutluluk getirmediği söylenebilir.

\section{Nüfus Yoğunluğu}

Türkiye genelinde 2012 yılı için nüfus yoğunluğu 98' dir.

Tablo 12. Nüfus Yoğunluğu Karşılaştırması (2012)

\begin{tabular}{lclc}
\hline En Mutlu İller & Nüfus Yoğunluğu & En Mutsuz İller & Nüfus Yoğunluğu \\
\hline Sinop & $35(-)$ & Tunceli & $12(-)$ \\
Afyonkarahisar & $49(-)$ & Osmaniye & $158(+)$ \\
Bayburt & $20(-)$ & Diyarbakır & $106(+)$ \\
Kirıkkale & $61(-)$ & Antalya & $101(+)$ \\
Kütahya & $48(-)$ & Hatay & $255(+)$ \\
\hline
\end{tabular}

\section{Kaynak: TÜIKK}

Not: Parantez içindeki “+” ve “-" işaretleri sırasıyla değişkenin Türkiye ortalamasının üstünde veya altında olduğunu ifade etmektedir.

Mutlu illerin tamamında nüfus yoğunluğu Türkiye ortalamasının altında iken mutsuz illerin Tunceli hariç diğerlerinde nüfus yoğunluğu ortalamanın üzerindedir. Tunceli Türkiye'de nüfus yoğunluğunun en düşük olduğu ildir. Tablo 12'ye göre nüfus yoğunluğu arttıkça mutluluk düzeyinin azaldığını söylemek mümkündür.

\subsection{Yerel Seçimleri Sonuçları Bağlamında Değerlendirme}

Yaşam memnuniyeti araştırması sonuçlarında memnuniyetin yüksek olduğu illerden hiçbirinin büyükşehir belediyesi olmaması dikkat çekicidir. Buna karşın büyükşehir belediyeleri olan Diyarbakır, Antalya ve Hatay ${ }^{1}$ ise en düşük memnuniyetin olduğu ilk beş il arasındadır.

Yaşam memnuniyeti araştırması sonuçlarının seçmen tercihleri ile paralel olup olmadığını analiz etmek amacıyla 30 Mart 2014 yerel seçimlerinde yukarıdaki illerin

\footnotetext{
${ }^{1}$ Hatay, 6360 sayılı “On Üç İlde Büyükşehir Belediyesi Ve Yirmi Altı İlçe Kurulması İle Bazı Kanun ve Kanun Hükmünde Kararnamelerde Değişiklik Yapılmasına Dair Kanun” ile Büyükşehir Belediyesi olmuştur.
} 
belediyelerini yöneten siyasi partilerin el değiştirip değiştirmediği aşağıdaki tabloda sunulmuştur.

Tablo 13. 2009-2014 Yerel Seçimleri Karşılaştırması

\begin{tabular}{llllll}
\hline En Mutlu İller & 2009 & 2014 & En Mutsuz İler & 2009 & 2014 \\
\hline Sinop & CHP & CHP & Tunceli & DTP & BDP \\
Afyonkarahisar & AKP & AKP & Osmaniye & MHP & MHP \\
Bayburt & AKP & AKP & Diyarbakır & DTP & BDP \\
Kırıkkale & AKP & AKP & Antalya & CHP & AKP \\
Kütahya & AKP & AKP & Hatay & AKP & CHP \\
\hline
\end{tabular}

Yaşam memnuniyet araştırması sonuçlarına göre en mutlu beş ilin hiçbirinde 2014 yerel seçimlerinde belediyelerinde siyasi parti değişikliği olmamıştır. Memnuniyetin en az olduğu illerde ise Tunceli, Osmaniye ve Diyarbakır'da belediyeyi yöneten siyasi partiler değişmemişken (DTP 2009'da kapatılmış olup benzer ideoloji ile BDP kurulduğundan aynı parti gibi kabul edilmiştir) Antalya'da yönetim $\mathrm{CHP}^{\prime}$ den AKP'ye, Hatay'da ise AKP'den $\mathrm{CHP}^{\prime}$ ye geçmiştir.

Belediyelerin el değiştirmesinde birçok faktörün (özellikle ideolojik faktörler) bulunması muhakkak olup yaşam memnuniyetinin de bu durumda etkisi olup olmadığının araştırılması ayrıca bir çalışma konusu olabilecek derinliktedir.

\section{SONUÇ}

"Yaşam Memnuniyeti Araştırması" TÜİK tarafından ilk defa 2013 yılında il düzeyinde yapılmış ve yayınlanmıştır. Çalışmada YMA sonuçlarına göre en mutlu ve en mutsuz beş ilin ekonomik, sosyal ve siyasi göstergeleri analiz edilerek mutluluk düzeylerinde etkisi olup olmadığını gözlemlemek amaçlanmıştır. İl düzeyinde yayınlanan ve ulaşılabilen ve belirgin sonuç veren göstergeler bağlamında veriler görsel olarak sunulmuş ve karşılaştırmalar yapılmıştır.

Ekonomik göstergelere göre; mutlu illerde işsizlik oranları, konut satış sayısı oranları, genel bütçe vergi gelirlerinde toplam tahsilat içindeki payı, genel bütçe vergi gelirleri tahsilat/tahakkuk oranı mutsuz illere göre düşük; bin kişi başına otomobil sayısı ve ev sahibi olan hanehalkı oranı fazladır.

Sosyal göstergelere göre; mutlu illerde boşanma hızı, kişi başına elektrik tüketimi, nüfus yoğunluğu mutsuz illere kıyasla düşük; ilkokullarda net okullaşma oranı ve yüz bin kişi başına hastane yatak sayısı daha fazladır.

2009-2014 yerel seçimleri sonuçları karşılaştırıldığında mutlu illerin tamamında belediye yönetiminde siyasi parti tercihi değişmemişken mutsuz illerin ikisinde (Antalya ve Hatay) belediye yönetimi farklı siyasi partilere geçmiştir. Diğer üç il belediyesinin el değiştirmemiş olması ise ideolojik nedenlere dayandırılabilir.

Yaşam memnuniyeti araştırması anket yöntemiyle uygulandığından birçok açıdan eleştirilmektedir. Özellikle yanıt aranan soruların memnuniyet düzeyini ölçmede yeterliliği, görüşüne başvurulan katılımcıların ana kütleyi temsil kabiliyeti, katılımcı sayısının yeterliliği, coğrafi bölge ve il düzeyinde katılımın sağlıklı bir şekilde karşılanmış olup olmadığı tartışılmaktadır. 
Tüm bu eleştirilere rağmen Resul Kurt'un (2014) TÜİK'in sunumunda kullanıldığını bahsettiği şu ifade durumu özetlemektedir: "İstatistik; geçmişi anlamanın, bugünü yönetmenin ve geleceği planlamanın anahtarıdır."

\section{KAYNAKÇA}

http://www.gib.gov.tr/fileadmin/user_upload/VI/GBG/Tablo_55.xls.htm

https://portal.muhasebat.gov.tr/mgmportal/faces/anasayfa?_adf.ctrl-state=xandsdsju_573

http://www.tuik.gov.tr/PreHaberBultenleri.do?id=18507

http://www.tuik.gov.tr/ilGostergeleri/index.html

Karataş, S. (1990). Yaşlılıkta Yaşam Doyumu ve Etkileyen Etmenler, Hacettepe Üniversitesi Sosyal Hizmetler Meslek Yüksek Okulu Dergisi, 8: 105-140.

Kurt, R. (2014). Yaşam Memnuniyeti Araştırması Bizlere Ne Söylüyor?, Dünya Gazetesi, 18.04.2014.

Pacione, M. (2003). Urban Environmental Quality and Human Wellbeing- a Social Geographical Perspective, Landscape and Urban Planning, 65: 19-30.

Veenhoven, R. (1996). The Study of Life Satisfaction, Comparative Study of Satisfaction with Life in Europe, Eötvös University Pres. 